Aim of the study: To evaluate outcome, costs and treatment differences in rectal cancer patients between various regions in Poland.

Material and methods: Data from the Polish National Health Fund of all patients with rectal cancer diagnosed and treated between 2005 and 2007 were analyzed. Overall, relative 5 -year survival and the percentage of patients receiving chemotherapy, radiotherapy and surgery were analyzed. The possible influence of cost of treatment per patient and mean number of rectal cancer patients per surgical oncologist were analyzed as well. Results: In total 15,281 patients with rectal cancer were diagnosed and treated in Poland in 2005-2007 within the services of the National Health Fund. The overall, relative 5-year survival rate was $51.6 \%$. Curative surgery was performed in $64.1 \%$ of patients. Radiotherapy and chemotherapy were used in $47.5 \%$ and $60.7 \%$ of patients, respectively. The mean cost of treatment of one rectal cancer patient was 32,800 PLN and there were 49.8 rectal cancer patients per specialist in surgical oncology. Important differences between regions were found in all these factors, but without a significant influence on survival. A correlation between numbers of patients per specialist in different voivodeships and survival rates was observed, as well as a correlation between percentage of surgical resection in voivodeships and survival rates $(p=0.07)$. Conclusions: Results of treatment of colorectal cancer in Poland improved significantly during the last decade. There exist however, important disparities between regions in terms of method of treatment, costs and outcomes.

Key words: rectal cancer, prognosis, registries, treatment outcome.

Contemp Oncol (Pozn) 2015; 19 (5): 400-409 DOI: $10.5114 /$ wo. 2015.56010

\section{Variation in treatment modalities, costs and outcomes of rectal cancer patients in Poland}

\author{
Krzysztof J. Herman ${ }^{1}$, Andrzej L. Komorowski ${ }^{1}$, Wojciech M. Wysocki ${ }^{1}$, \\ Jacek Tabor ${ }^{1}$, Roman M. Herman ${ }^{1}$, Andrzej Śliwczyński ${ }^{2}$
}

\author{
1Department of Surgical Oncology, Maria Skłodowska-Curie Memorial Institute \\ of Oncology Cancer Centre, Warsaw, Poland \\ 2Public Health Department, Health Sciences Faculty, Medical University, Łódź, Poland, \\ National Health Protection Fund, Warsaw, Poland
}

\section{Introduction}

Many studies have shown important variations in the treatment modalities and outcome between hospitals [1, 2]. The regional and between-hospital differences can only partially be explained by the different volume and case mix that every hospital manages [3].

In Poland, colorectal cancer incidence and mortality are on a steady rise in almost all regions [4]. The implementation of national guidelines, which has been shown in other countries to improve outcomes in rectal cancer [5], has been introduced in Poland. Unfortunately, even with the implementation of the Polish national guidelines for the treatment of colorectal cancers, there are important regional differences in terms of adherence to the guidelines and outcomes of treatment.

In the literature there are conflicting data on whether the differences in treatment modalities of patients with rectal cancer influence outcome. An association between hospital volume and outcome has been reported by some and denied by others [6-10]. Also the analysis of the type of hospital (university hospital, community or county hospital) has shown conflicting results $[11,12]$.

In this study we analyzed regional differences and outcomes in the treatment modalities used to treat rectal cancer patients. We also tried to identify which factors are responsible for the differences in overall survival between regions.

\section{Material and methods}

In Poland, all newly diagnosed cancers should be registered in the nationwide National Cancer Registry. The data are provided by all hospitals at the moment when a new cancer case is diagnosed, and at the same time the cancer should be staged according to the newest version of the TNM classification [13]. On the other hand, the National Health Fund (Narodowy Fundusz Zdrowia, NFZ) is obliged to ensure and cover the costs of treatment of all patients within the system. There is only a small number of oncological patients treated out of this system. To allow for analysis of the costs borne by the system and the results of treatment, a series of coding systems are used for every patient. For coding of the tumor site and type the International Classification of Diseases is used [14]. Unfortunately, there are no data on cancer stage in the system yet. The calculation of the costs is based on the same data. The law in Poland does not require the national insurer (NFZ) to cover the actual costs of a procedure.

The outcomes of patients with colorectal cancer treated in 2005-2007 were compared to those treated in 2000-2002. We compared results for the 
colon and rectal cancer group as a whole because there was no information about 5-year survival rates of the subgroup of rectal cancer patients treated previously. Survival data from the years 2000-2002 were obtained from the National Cancer Registry, as there were no similar data available from the National Health Fund.

\section{Statistical methods}

For statistical analysis we used Statistica 10 for Windows. Univariate and multivariate analysis of the available data was performed.

\section{Patients}

In Poland 41,287 patients were diagnosed with colorectal cancer from 2005 to 2007. Data of all patients with invasive rectal cancer diagnosed and treated between 2005 and 2007 within the National Health Fund system in Poland were selected for the study $(n=15,281)$.

\section{Regions, hospitals, surgeons}

Poland is divided into 17 regions (voivodeships). There exist important differences between regions in terms of population, income per capita and centralization of cancer care (not all regions have a dedicated cancer center). Also, in regions with a dedicated cancer center not all cancer patients are treated there, as many patients are treated in university and community or county hospitals. In Poland there is a subspecialty called surgical oncology, and the majority of surgical oncologists are general surgeons with two additional years of training in cancer centers. However, there is no legal obligation that would require all cancer patients to be treated by surgeons with this particular subspecialty. Some of the operations for rectal cancer are performed by general surgeons and some by surgical oncologists (who are also general surgeons).

\section{Results}

Survival

\section{Colorectal cancer}

Relative 5-year survival was $52.8 \%$ for the whole colorectal patient group treated between 2005 and 2007 (ranging in voivodeships from $48.1 \%$ to $56.1 \%$ ). Comparison (Fig. 1) of current and historical data for all regions in Poland shows an important rise in the outcomes. Five-year survival in the years 2000-2002 was 43.7\% and ranged depending on the region from $36.3 \%$ to $45.7 \%$. When comparing data for each region separately for both periods we found that rates rose for every region from $8 \%$ to $12.5 \%$ (mean rise of $9.1 \%$ ).

\section{Rectal cancer}

There was an $8.4 \%$ difference in relative 5 -year survival rate between Polish voivodeships (47.1\% to $55.5 \%$; mean 51.6\%) (Fig. 2).

Radiotherapy was used in $47.5 \%$ of patients (33.5\% to $59.4 \%$ depending on the region, Fig. 3). The use of radiotherapy in each region did not influence overall 5-year survival rates $(p=0.26)$ (Fig. 4).

Chemotherapy (adjuvant or neoadjuvant) was used in $60.7 \%$ (51.4\% to $75.3 \%$ depending on the region) of patients (Fig. 5). The use of chemotherapy in each region did not influence overall 5-year survival rates $(p=0.28)$ (Fig. 6).

Surgery with curative intent was performed in $64.1 \%$ (45.5\% to $70.6 \%$ depending on the region) of patients (Fig. 7). We observed a trend toward better survival rates in regions with more radical surgery cases, although this trend did not reach the level of statistical significance $(p=0.07)$ (Fig. 8).

Analysis of percentages of hepatic metastasectomies performed in rectal cancer patients showed significant differences between voivodeships; mean 1.5\% (range 0.252.5\%) (Fig. 9).

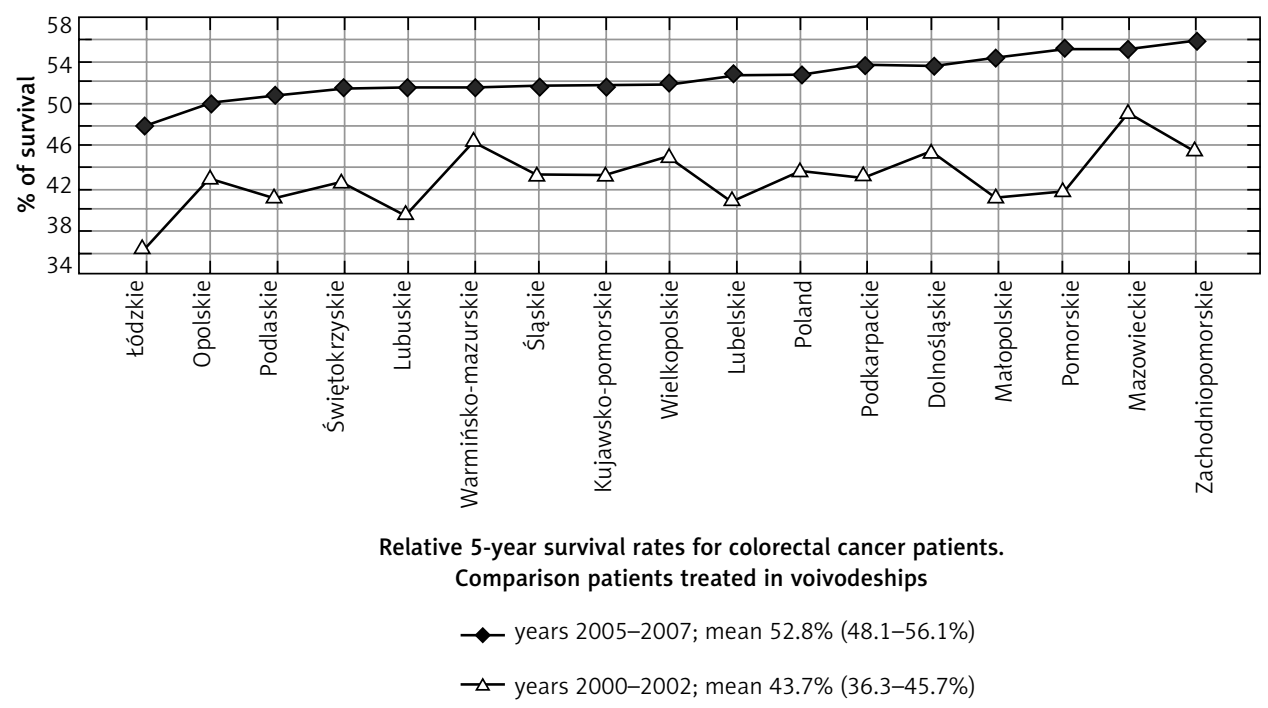

Fig. 1. Relative 5-year survival rates for colorectal cancer patients. Comparison of patients treated in voivodeships in 2005-2007 vs. 20002002 


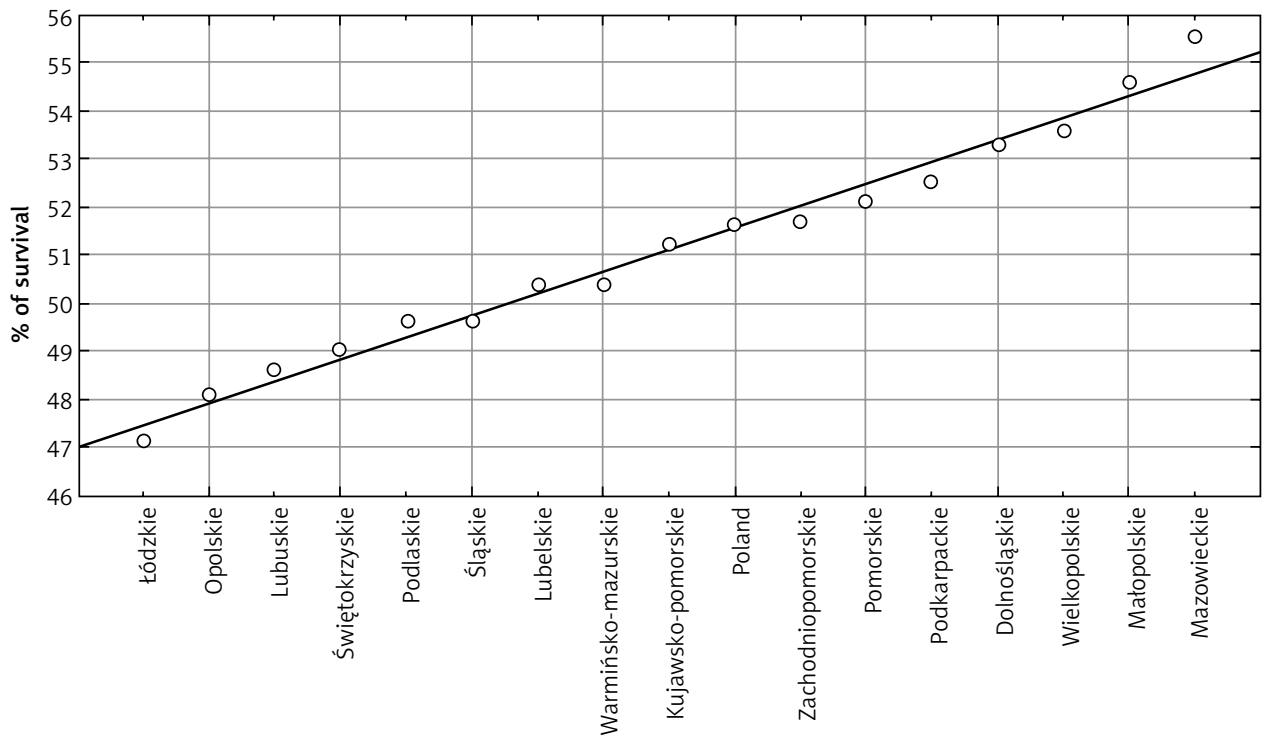

Relative 5-year survival rates for rectal cancer patients treated in 2005-2007 (in voivodeships mean $51.6 \%$ [47.1-55.5\%])

Fig. 2. Relative 5-year survival rates for rectal cancer patients treated in 2005-2007

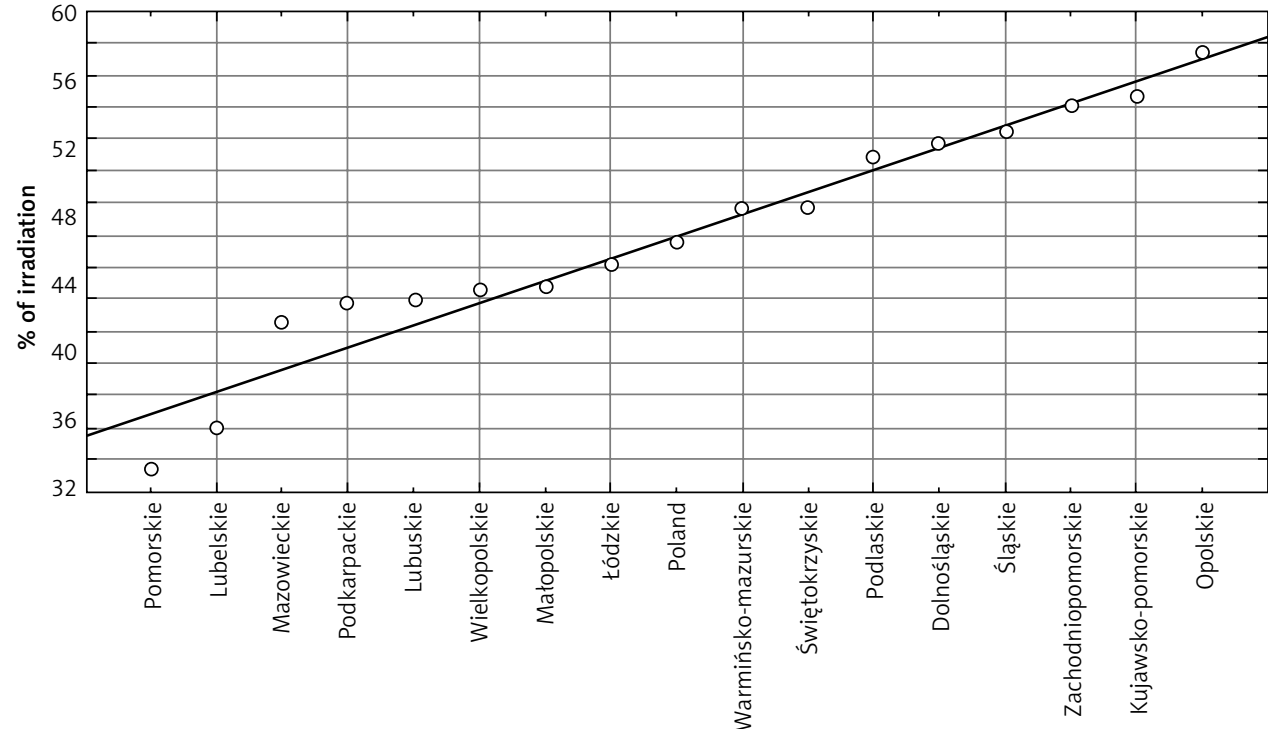

Rate of rectal cancer patients received irradiation therapy (in voivodeships mean $47.5 \%$ [33.5-59.4\%])

Fig. 3. Rate of rectal cancer patients receiving irradiation therapy

We also looked at the mean number of rectal cancer patients per surgical oncologist in each region. These numbers showed important variations among regions and ranged from 28 to 114 patients/specialist (mean 50) (Fig. 10). We did not find a statistically significant relation but only a trend between the number of patients per surgical oncologist per region and the 5-year overall survival rate
( $p=0.07$ ) (Fig. 11). It is important to note, however, that this number does not represent the actual workload of each surgical oncologist but only the number of patients in a particular region divided by the number of surgical oncologists practicing in this region, without taking into account the number of general surgeons and coloproctologists who take care of these patients. 


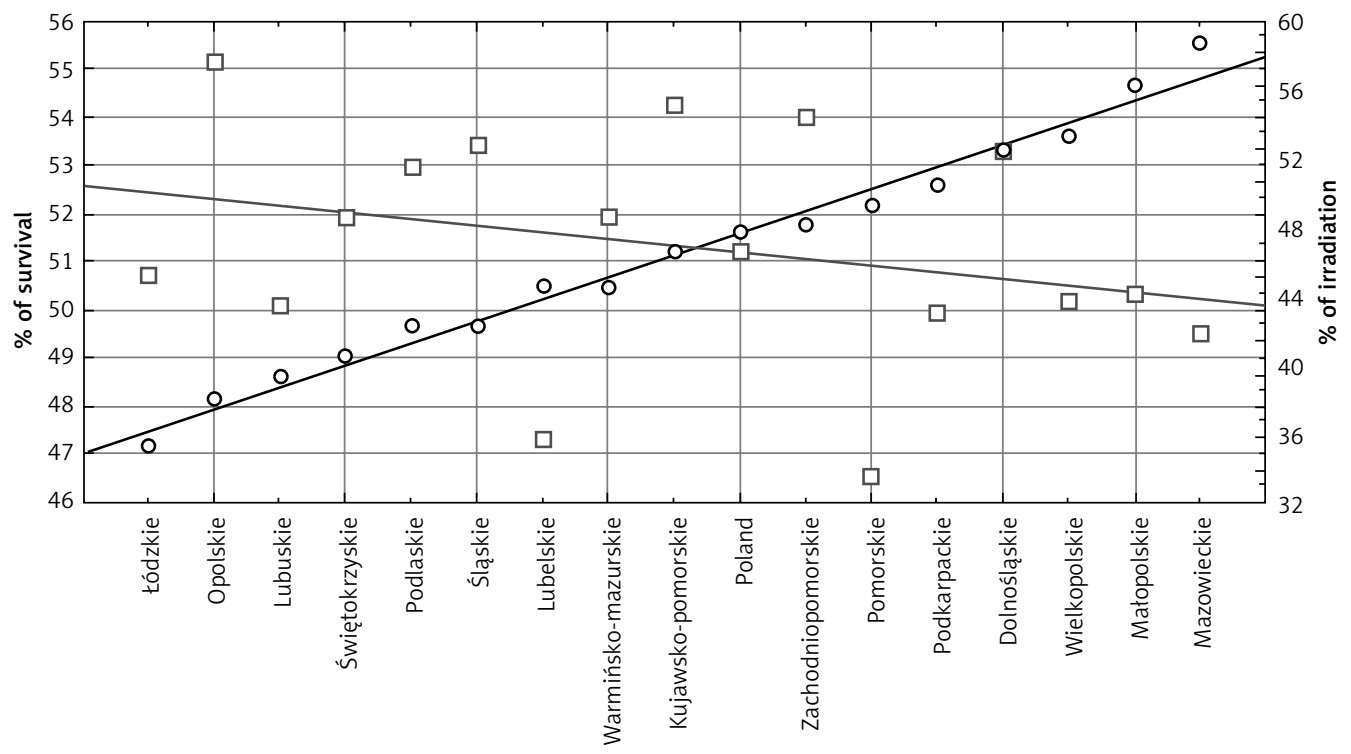

Relative 5-year survival rates of rectal patients and rate of patients received irradiation therapy (in voivodeships $p=0.26$ )

- - survival

$-\square-$ irradiation

Fig. 4. Relative 5-year survival rates of rectal cancer patients and rate of patients receiving irradiation therapy

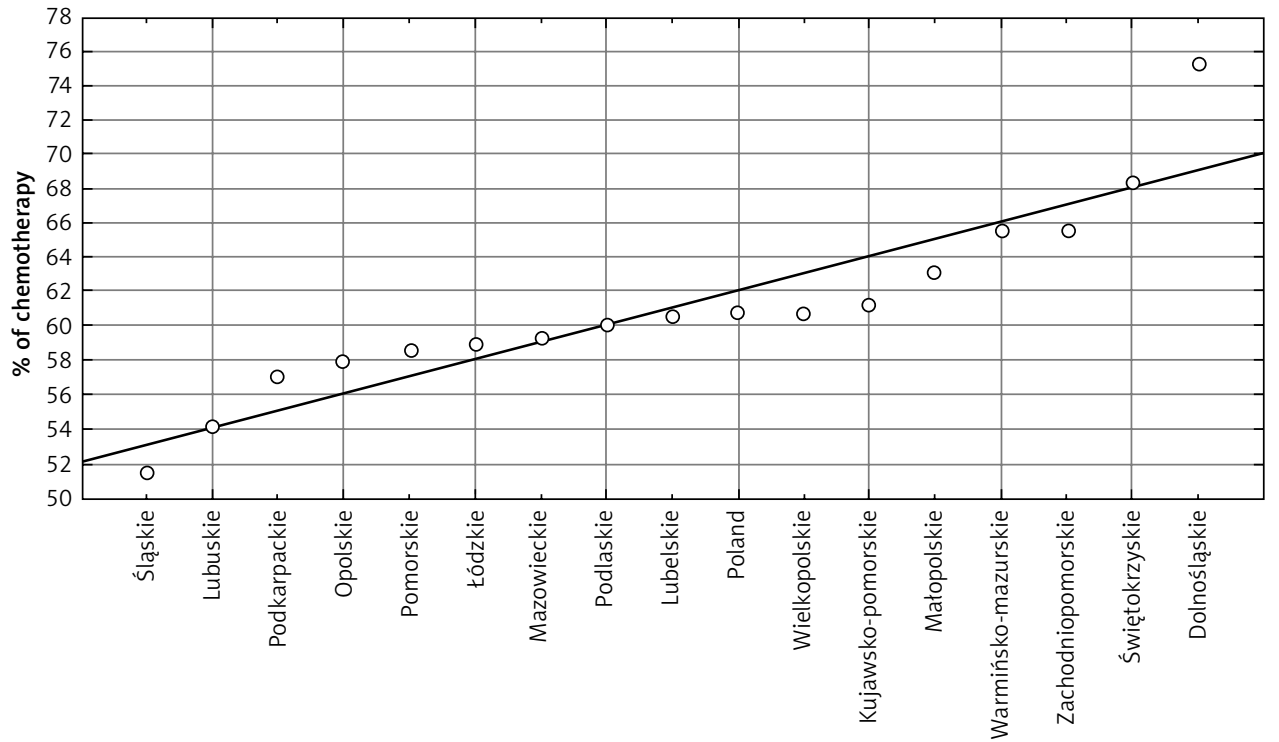

Rate of rectal cancer patients received chemotherapy (in voivodeships mean $60.7 \%$ [51.4-75.3\%])

Fig. 5. Rate of rectal cancer patients receiving chemotherapy

\section{Costs}

The mean cost of treatment of rectal cancer patient was 32,800 Polish zloty (PLN) (7,800 EUR; EUR = 4.2 PLN) (Fig. 12). Mean cost of surgery was 6500 PLN (1540 EUR), mean cost of radiotherapy was 7200 PLN (1700 EUR) and of chemotherapy was 18,300 (4340 EUR). The differences between regions in the mean costs of treatment were important and ranged from 29,300 PLN (6,900 EUR) to 38,500 PLN (9,140 EUR). The different costs of treatment in each voivodeship were analyzed to find whether there is a relation between cost of treatment and overall survival in a region. When data for all regions were compared, we found no statistically significant differences in terms of 5-year survival rates for each region (Fig. 13). Interestingly we also failed to find 


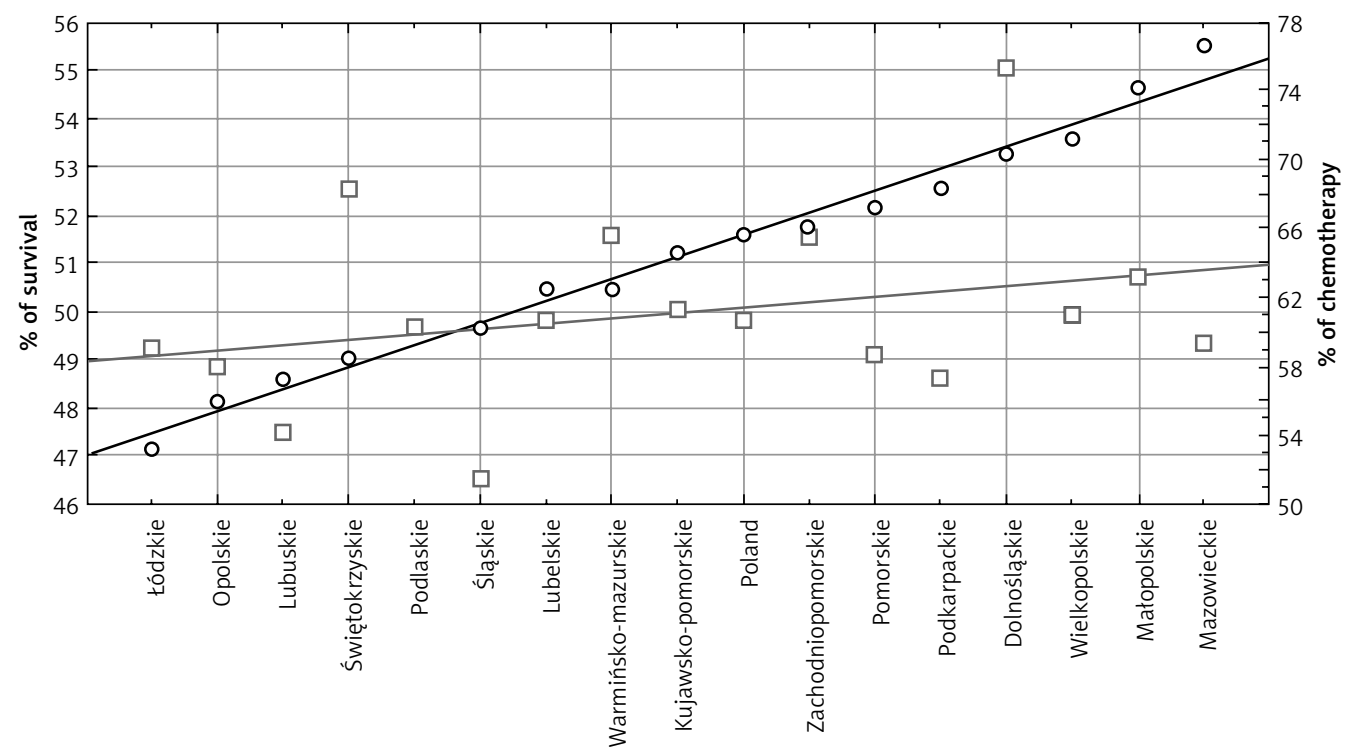

Relative 5-year survival rates of rectal patients and rate of patients received chemotherapy (in voivodeships $p=0.28$ )

- - survival

$-\square$ chemiotherapy

Fig. 6. Relative 5-year survival rates of rectal patients and rate of patients receiving chemotherapy

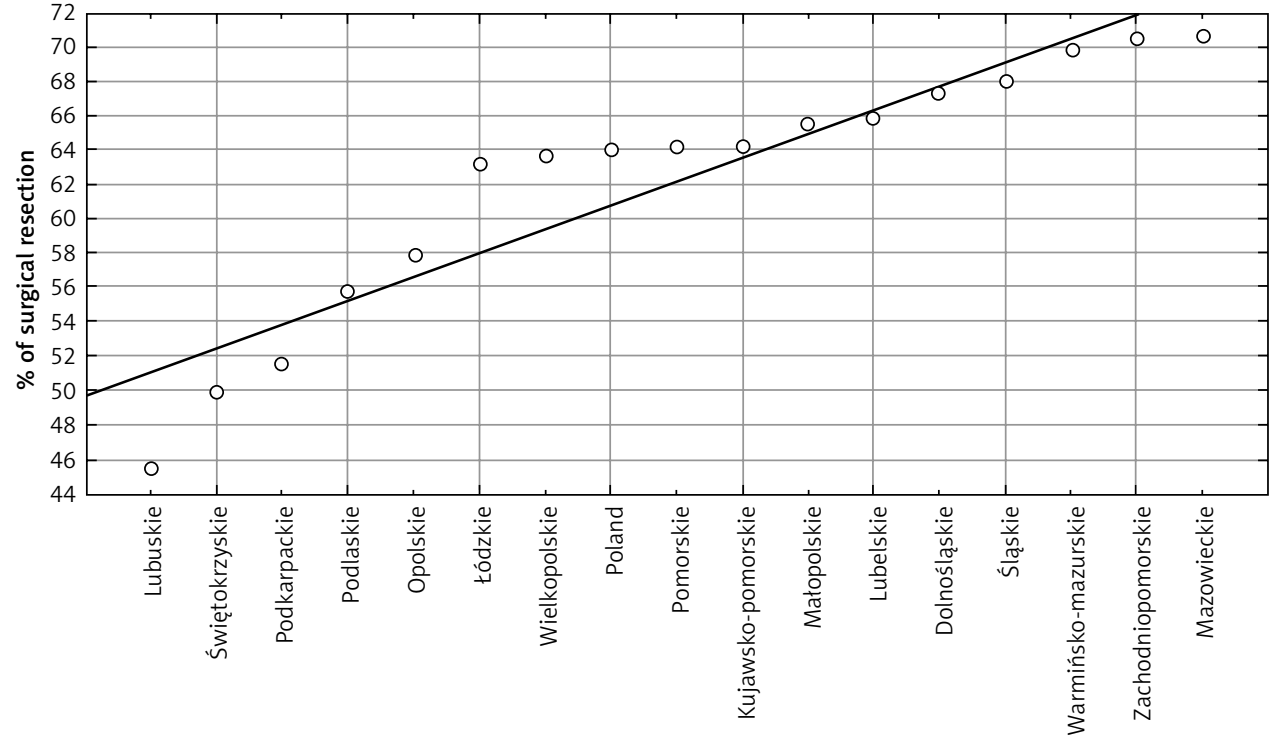

Percentage of rectal cancer patients treated with surgical resection

(in voivodeships mean $64.1 \%$ [45.5-70.6\%)

Fig. 7. Percentage of rectal cancer patients treated with surgical resection

a statistically significant correlation between the cost of treatment in each region and the incidence of chemotherapy (adjuvant or neoadjuvant), radiotherapy or surgery.

\section{Discussion}

In this nationwide population-based study evaluating National Health Fund data of 15,281 patients with rectal cancer diagnosed and treated in Poland in the period from 2005 to 2007, we found important differences in treatment modalities and outcomes between regions.

The relative 5 -year survival rate of $52 \%$ observed in this analysis is disturbingly lower when compared to the figures from the USA (66\%) [15], the United Kingdom (56\%) [16] or Norway (66\%) [17]. On the other hand, only a few years ago 


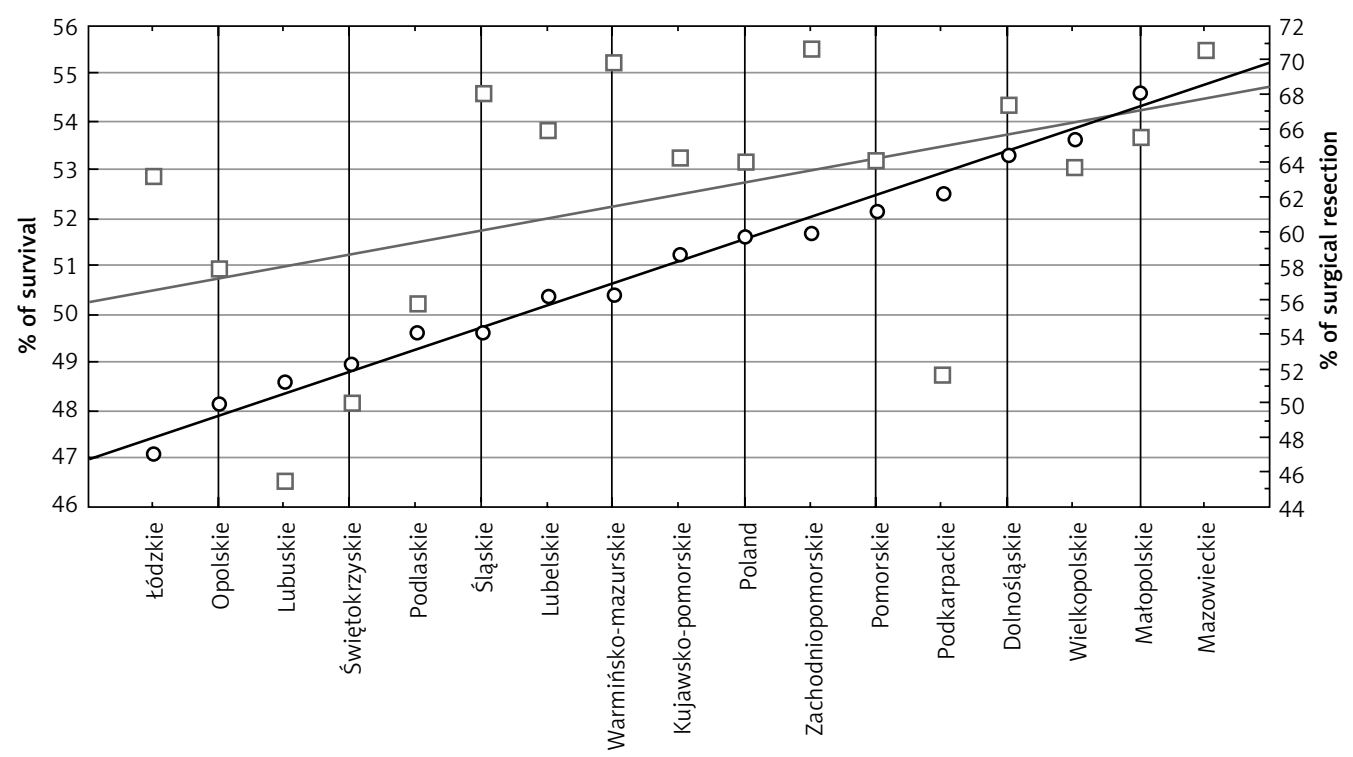

Relative 5-year survival rates of rectal patients and rate of patients after surgical resection (in voivodeships $p=0.07 ; R 2=0.15$ )

$\multimap$ survival

$-\square-$ surgical resection

Fig. 8. Relative 5-year survival rates of rectal cancer patients and rate of patients after surgical resection

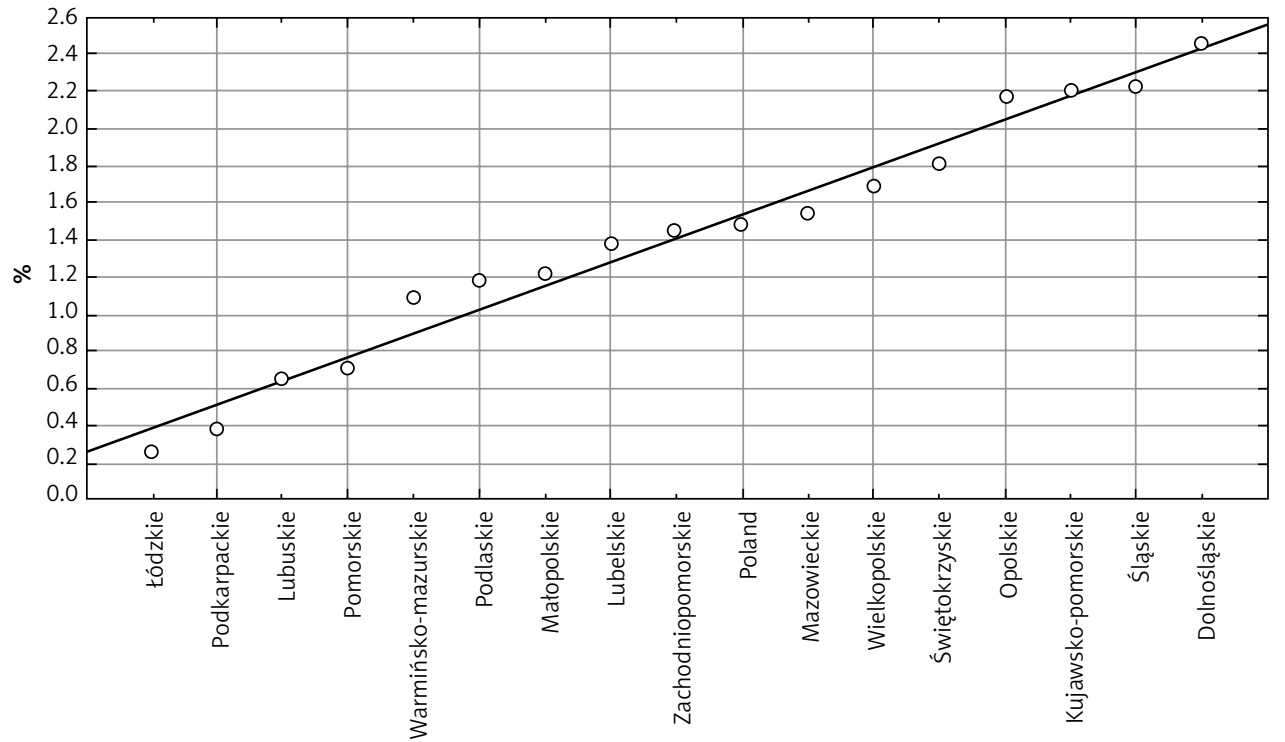

Percentage of rectal cancer patients after hepatic metastasectomy

(in voivodeships mean $1.5 \%$ [0.25-2.5\%])

Fig. 9. Percentage of rectal cancer patients after hepatic metastasectomy

the figures for 5-year survival were much lower for all regions and rose by an average of $9.1 \%$ during this time span. This important step forward can be partially explained by the introduction of the guidelines in the treatment of rectal cancer, which has been shown to improve outcomes [5].

The current standard of care in Poland requires that for the treatment of rectal cancer patients with stage III and locally advanced stage II tumors without distant metastasis receive radio-chemotherapy or radiotherapy preceding resection to reduce the risk of local recurrence [18]. In our study we found important variations between regions in terms of incidence of radiotherapy ranging from $33.5 \%$ to $59.4 \%$. While the higher numbers are similar to numbers in other national data sets (USA 50\%, The Netherlands 54\%) 


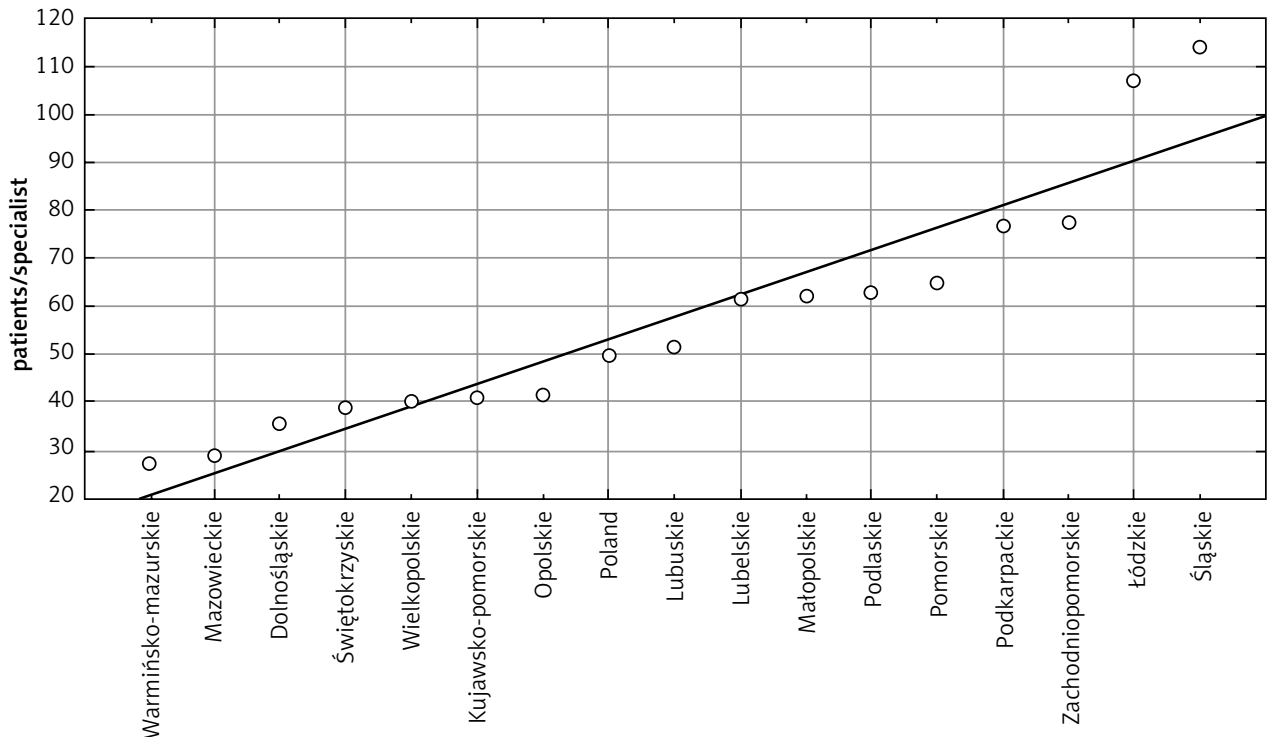

Number of rectal cancer patients per specialist (oncological surgeon) (in voivodeships mean $49.8[27.5-114)$

Fig. 10. Number of rectal cancer patients per specialist (oncological surgeon)

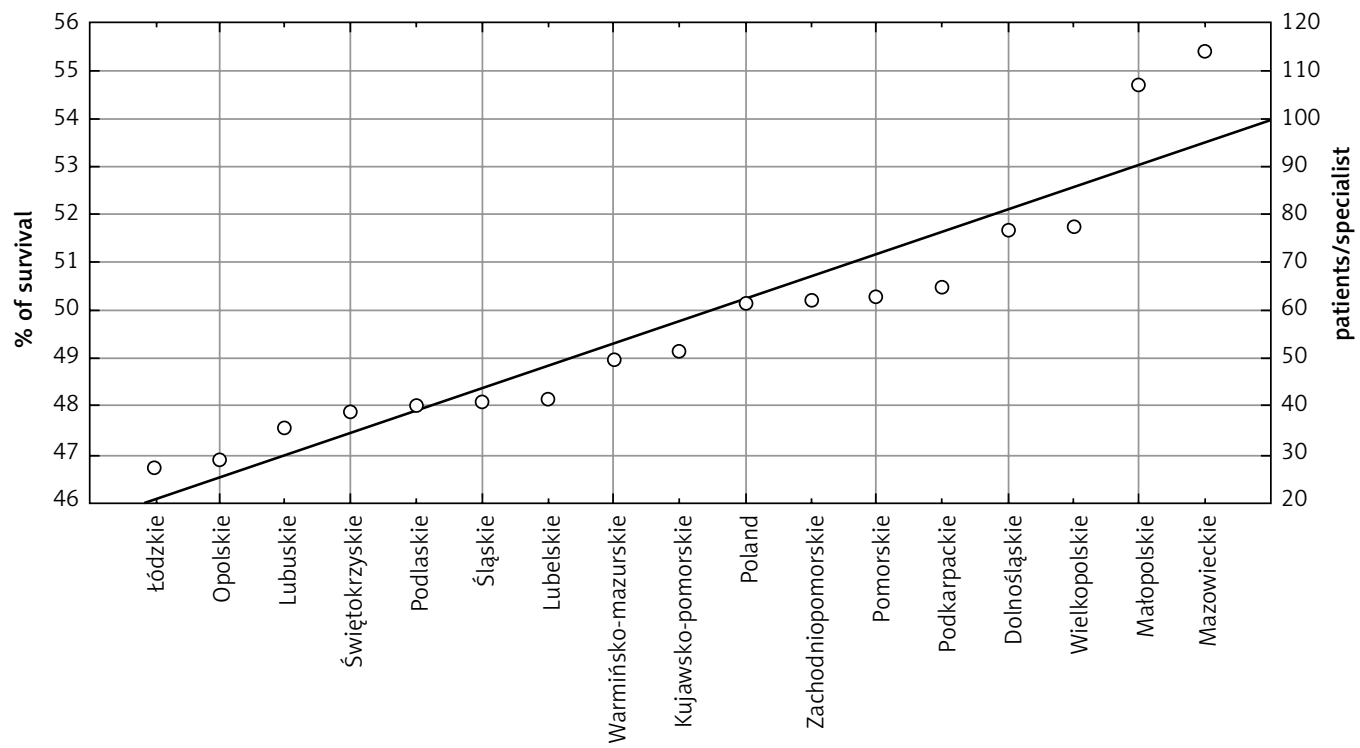

Relative 5-year survival rates of rectal patients and number of patients per specialist (oncological surgeon) (in voivodeships $p=0.07, R 2=0.39$ )

- - survival

- pts/specialist

Fig. 11. Relative 5-year survival rates of rectal cancer patients and number of patients per specialist (oncological surgeon)

the numbers for some Polish regions are definitely too low, even taking into account a different case mix. The differences in the approach to preoperative radiotherapy between surgeons and hospitals despite clear and unified national criteria are a constant finding in other publications. A Korean questionnaire study showed that surgeons in university hospitals are more likely to refer patients with rectal cancer for preoperative radiotherapy [19]. However, Dutch results showed that patients diagnosed in a teaching hospital were less likely to receive preoperative radiotherapy [3].

Interestingly, we could not find a statistically significant correlation between the incidence of radiotherapy in a region and probability of overall survival. This finding can be explained by reports confirming that preoperative radio- 


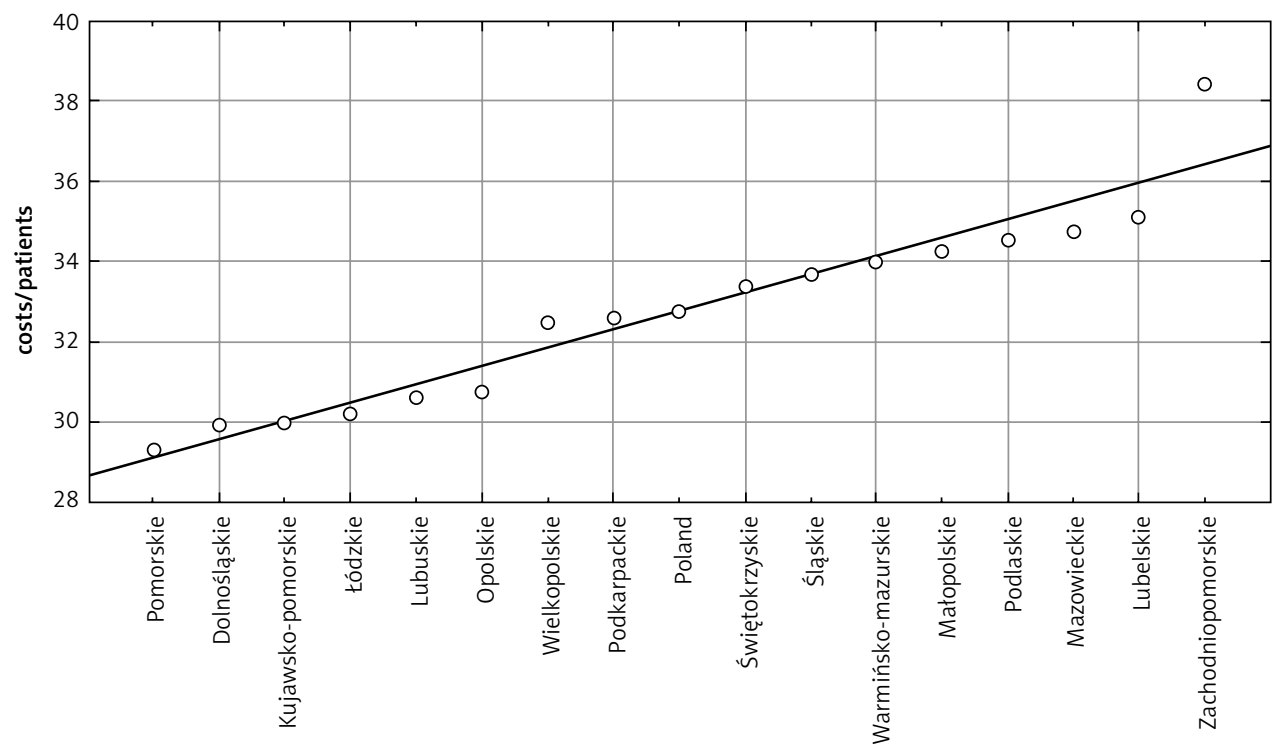

Costs treatment patients with rectal cancer (in tousands PLN per patients) (in voivodeships mean 32.8/pt [29.3-38.5])

Fig. 12. Costs of treatment of patients with rectal cancer

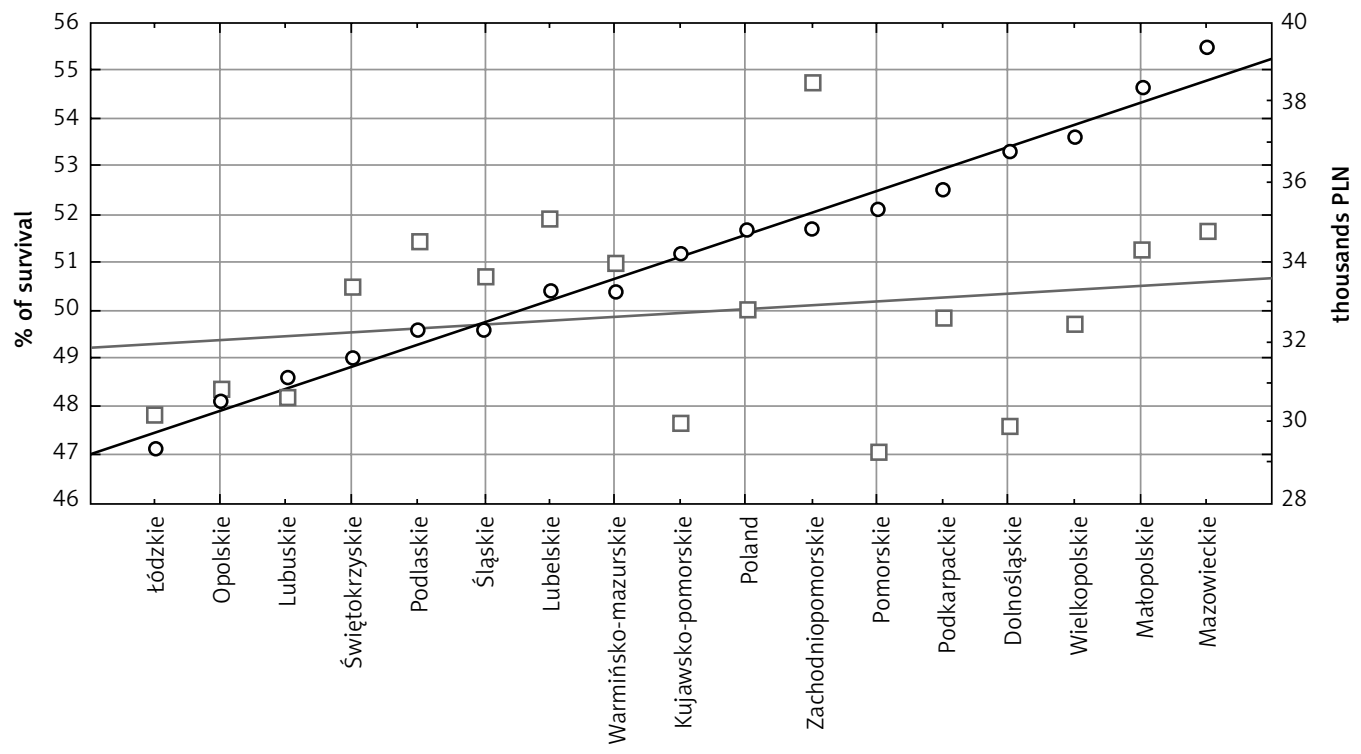

Relative 5-year survival rates of rectal patients and costs of patients treatment (in voivodeships $p=0.37$ )

$$
\begin{aligned}
& -\circ \text { survival } \\
& -\square-\text { cost/patients }
\end{aligned}
$$

Fig. 13. Relative 5-year survival rates of rectal cancer patients and costs of patient treatment

chemotherapy can indeed lower local recurrence rate but at the same time may have no influence on overall survival [20]. However, it should be underlined that in our study we did not analyze the influence of regional differences in case mix on the outcome. Thus, it is possible that the differences in incidence of radiotherapy mirror important differences in the tumor burden in each regional patient population.

Similar disparities were observed between regions in terms of chemotherapy treatment. Once again, we observed no statistically significant correlation between chemotherapy treatment and overall survival probability in 
each region. Adjuvant and neoadjuvant chemotherapy has been shown to influence both disease-free [21] and overall survival [22]. Therefore, our results probably reflect the differences in the stage of the disease between regions.

The high variation in the incidence of surgery with curative intent (45.5\% to $70.6 \%$ depending on the region) is probably a reflection of different stage of disease as well. But this is only a partial explanation. One should bear in mind that even currently in Poland about $50-60 \%$ of cases of colorectal cancer are diagnosed and treated at stage III and IV [4]. The influence of performing surgery with curative intent on overall survival was the strongest single factor influencing survival in our study, but it did not reach statistical significance.

Another factor that showed a trend toward reaching statistical significance was the impact of the mean number of rectal cancer patients per surgical oncologist in each region on survival. This finding is difficult to interpret due to the specific nature of this subspecialty in Poland and the fact that many general surgeons without formal surgical oncology training perform rectal cancer surgery as well. It seems likely that these two findings (surgical resection percentages and number of patients per specialist with their influences on survival) may indicate differences in quality of treatment of rectal cancer patients.

Another finding that came as a surprise was the low incidence of hepatic resection in the study group. The 1.5\% of rectal cancer patients undergoing liver resection for metastasis is much lower than the $6.1 \%$ reported in the North American study on Medicare beneficiaries [23]. This number seems very low. It is not clear why so few rectal cancer patients underwent hepatic resection. One explanation could be the low number of dedicated hepatopancreaticobiliary (HPB) centers in Poland (currently only 6 centers in Poland have an advanced HPB and liver transplant program).

The cost of treatment of rectal cancer patients in Poland was significantly lower than the same costs in Poland's western neighbor, Germany. The mean of 7,800 EURO paid in Poland is far from the 15,000 EURO to 21,300 EURO for early stages and from 29,800 EURO to 35,000 EURO for late stages reported by the German insurance system [24]. Similar numbers have been reported in France, where the mean cost of a year of treatment of a colorectal cancer patient has been found to be 24,966 EURO. The French analysis also showed the influence of stage on the total cost of care, with cost of treatment of stage I colorectal cancer of 17,596 EURO and 35,059 EURO for stage IV [25]. In our study no correlation was found between the cost of treatment of a rectal cancer patient in each region and the overall survival. Interestingly, we also failed to identify a correlation between higher cost and the probability of chemotherapy, radiotherapy or curative surgery treatment. While we cannot fully explain these findings, it is somewhat reassuring that lower costs of treatment in some regions in our study were not correlated with poorer survival.

In conclusion, despite the existence of the national treatment guidelines in Poland, there are important disparities between regions in terms of type of treatment, overall survival and costs. In the last few years we have observed a major improvement in the results of treatment of rectal cancer, but they are still worse than the results in the USA and Western Europe.

The authors declare no conflict of interest.

\section{References}

1. Chowdhury MM, Dagash H, Pierro A. A systematic review of the impact of volume of surgery and specialization on patient outcome. Br J Surg 2007; 94: 145-61.

2. Birkmeyer JD, Siewers AE, Finlayson EV, Stukel TA, Lucas FL, Batista I, Welch HG, Wennberg DE. Hospital volume and surgical mortality in the United States. N Engl J Med 2002; 346: 1128-37.

3. Elferink MA, Krijnen P, Wouters MW, et al. Variation in treatment and outcome of patients with rectal cancer by region, hospital type and volume in the Netherlands. Eur J Surg Oncol 2010; 36 Suppl 1: S74-82.

4. Klimczak A, Kempińska-Mirosławska B, Mik M, Dziki L, Dziki A. Colorectal cancer mortality in Poland - analysis of regional variation. Arch Med Sci 2014; 24: 63-7.

5. Kapiteijn E, Putter H, van de Velde C); Cooperative investigators of the Dutch ColoRectal Cancer Group. Impact of the introduction and training of total mesorectal excision on recurrence and survival in rectal cancer in The Netherlands. Br J Surg 2002; 89: 1142-9.

6. Engel J, Kerr J, Eckel R, et al. Influence of hospital volume on local recurrence and survival in a population sample of rectal cancer patients. Eur J Surg Oncol 2005; 31: 512-20.

7. Simunovic M, To T, Baxter N, et al. Hospital procedure volume and teaching status do not influence treatment and outcome measures of rectal cancer surgery in a large general population. J Gastrointest Surg 2000; 4: 324-30.

8. Hodgson DC, Zhang W, Zaslavsky AM, Fuchs CS, Wright WE, Ayanian JZ. Relation of hospital volume to colostomy rates and survival for patients with rectal cancer. J Natl Cancer Inst 2003; 95: 708-16.

9. Herman K, Lesniak T, Wysocki W, Komorowski A. Surgeon related quality in colorectal and breast cancer surgery. The Internet Journal of Surgery 2001; 3: 1.

10. Wibe A, Eriksen MT, Syse A, Tretli S, Myrvold HE, Søreide O; Norwegian Rectal Cancer Group. Effect of hospital caseload on long-term outcome after standardization of rectal cancer surgery at a national level. Br J Surg 2005; 92: 217-24.

11. Simons AJ, Ker R, Groshen S, et al. Variations in treatment of rectal cancer: the influence of hospital type and caseload. Dis Colon Rectum 1997; 40: 641-6.

12. Blomqvist P, Ekbom A, Nyrén O, Krusemo UB, Bergström R, Adami HO. Survival after rectal cancer: differences between hospital catchment areas. A nationwide study in Sweden. Gut 1999; 45: 39-44.

13. Wittekind C, Greene FL, Hutter RVP, Klimpfinger M, Sobin LH (eds.). TNM atlas. $5^{\text {th }}$ ed. Springer-Verlag, Berlin 2004.

14. Fritz A, Percy C, Jack A, et al. International classification of diseases for oncology. $3^{\text {rd }}$ ed. WHO, Geneva 2000.

15. http://seer.cancer.gov/statfacts/html/colorect.html.

16. http://www.cancerresearchuk.org/cancer-info/cancerstats/types/ bowel/survival/bowel-cancer-survival-statistics\#one.

17.http://www.kreftregisteret.no/Global/Cancer\%20in\%20Norway/2012/CIN_2012-web.pdf.

18. Herman K. National Surgical Oncology Guidelines. http://www. chirurgiaonkologiczna.org.pl/attachments/article/25/2014\%20 RAK\%20JELITA\%20GRUBEGO.pdf.

19. Lee SI, Park YA, Sohn SK. A survey on the impact of operation volume on rectal cancer management. J Korean Med Sci 2007; 22: S86-90.

20. Pătraşcu T, Doran H, Mihalache O. Preoperative radiotherapy in rectal cancer treatment - is it really a golden standard? Chirurgia (Bucur) 2014; 109: 185-90.

21. Glynne-Jones R, Counsell N, Quirke P, Mortensen N, Maraveyas A, Meadows HM, Ledermann J, Sebag-Montefiore D. Chronicle: re- 
sults of a randomised phase III trial in locally advanced rectal cancer after neoadjuvant chemoradiation randomising postoperative adjuvant capecitabine plus oxaliplatin (Xelox) versus control. Ann Oncol 2014; 25: 1356-62.

22. Uncu D, Aksoy S, Çetin B, et al. Results of adjuvant FOLFOX regimens in stage III colorectal cancer patients: retrospective analysis of 667 patients. Oncology 2013; 84: 240-5.

23. Cummings LC, Payes JD, Cooper GS. Survival after hepatic resection in metastatic colorectal cancer: a population-based study. Cancer 2007; 15: 718-26.

24. Haug U, Engel S, Verheyen F, Linder R. Estimating colorectal cancer treatment costs: a pragmatic approach exemplified by health insurance data from Germany. PLoS One 2014; 9: e88407.

25. Clerc L, Jooste V, Lejeune C, Schmitt B, Arveux P, Quantin C, Faivre J, Bouvier AM. Cost of care of colorectal cancers according to health care patterns and stage at diagnosis in France. Eur J Health Econ 2008; 9: 361-7.

\section{Address for correspondence}

Andrzej L. Komorowski, PhD

Department of Surgical Oncology

Maria Skłodowska-Curie Memorial Institute

of Oncology Cancer Centre

e-mail: alkomorowski@wp.p

Submitted: 08.10 .2014

Accepted: 20.04 .2015 